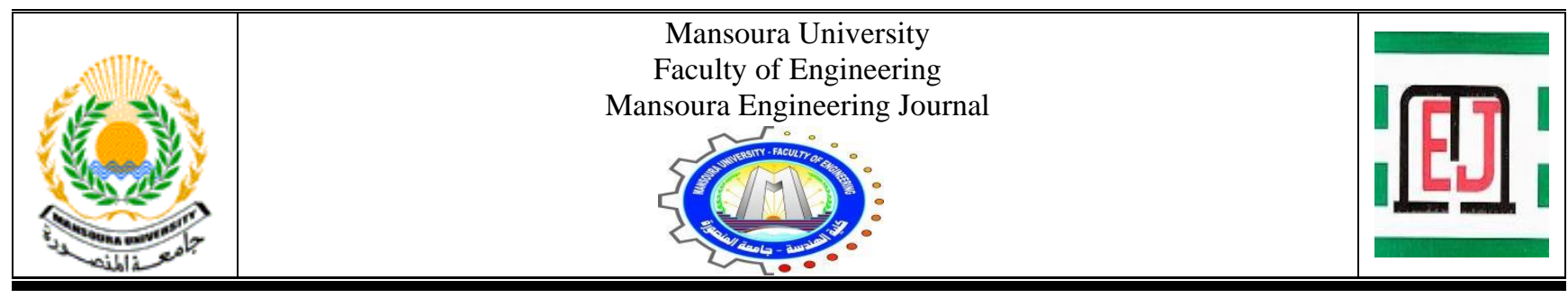

\title{
Performance Evaluation of Channel Modeling and Path Loss Measurements for Wireless Communication Systems in Urban and Rural Territories
}

\author{
*Yahia A. Zakaria, Ehab K. I. Hamad, A. S. Abd Elhamid and K. M. El-Khatib
}

\begin{tabular}{|lr|}
\hline \multicolumn{2}{|l|}{ KEYWORDS: } \\
Urban, & Rural, Path \\
Loss, $\quad$ Regression \\
Analysis, $\quad$ Wireless \\
Communication
\end{tabular}

\section{INTRODUCTION}

$\mathbf{J}$ AMES Clerk Maxwell proposed in 1865 that electromagnetic impulses have the ability to propagate over long distances at the speed of light. [1]. He determined that linear wave motion might be included among the possible solutions by adding the displacement to the existing term set of equations that regulate the equations of electromagnetics, known as the equations of Maxwell. As a result, electromagnetic waves should have the ability to travel

Received: (19 November, 2021) - Revised: (06 January, 2022) - Accepted: (19 January, 2022)

*Corresponding Author: Yahia A. Zakaria is an Assistant Researcher at the Engineering Research Division, National Research Centre (NRC), Cairo, Egypt (e-mail: yahia.zakaria1982@gmail.com).

Ehab K. I. Hamad is a Professor and the Head of the Electrical Engineering Department, Faculty of Engineering at Aswan University, Aswan, Egypt(e-mail: e.hamad@a swu.edu.eg) over basic separations. Heinrich Rudolf Hertz discovered the propagation of electric and magnetic waves in 1886 [2]. Predicting frequency allocations, base station coverage areas, appropriate selection of the magnitude of the electric field, analysis of interference, and power level modification all benefit from correct path loss estimation [3], [4]. It is possible to determine a path loss prediction model for mobile propagation environments by comparing existing path loss with practical measured data.

Furthermore, path loss is defined as the average attenuation of radio frequencies experienced by a sent signal when it

A. S. Abd Elhamid is a Professor and the Head of the Systems and Information Department, Engineering Research Division, National Research Centre (NRC), Cairo, Egypt (e-mail: ahmednrc64@gmail.com)

K. M. El-Khatib is a Professor and the Head of the Engineering Research Division, National Research Centre (NRC), Cairo, Egypt (e-mail: kamelced@hotmail.com) 
ultimately reaches the receiver, and is commonly expressed as the equation below [5]:

$$
P L(d)=P L\left(d_{0}\right)+10 n \log _{10}\left(\frac{d}{d_{0}}\right)
$$

Where, $d$ is the distance, $d_{0}$ is the $1 \mathrm{~km}$ reference point, $n$ is the exponent of path loss. Power arrives at the receiving antenna in free space, which is separated from the sending antenna by a distance $d$ is given by the following Friis free space equation [6]:

$$
P_{r}=\frac{P_{t} G_{r} \lambda^{2} G_{t}}{L(4 \pi d)^{2}}
$$

where $G_{t}$ and $G_{r}$ are antenna gain (both transmitting and receiving), respectively, $L$ is factor of system failure, $\lambda$ is the wavelength in meters. Free space is not an appropriate medium for mobile radio channels. Therefore, $P L$ model uses a parameter $I_{3}$ to refer to the distanced distance and the received power have a power law connection. Thus, path loss can be calculated as [6]:

$$
P L(d)=P L\left(d_{0}\right)+10 I_{3} \log \left(\frac{d}{d_{0}}\right)+X_{I f}
$$

Where, $I_{3}$ is generally equal 2 in free space, $X_{I f}$ refers to a mean of zero Standard deviation of a Gaussian random variable If that represents the received power's fluctuation.

Due to supporting technologies that allow for widespread deployment, mobile communication systems are currently growing at a rapid pace. When the idea of cellular was established in the $1960 \mathrm{~s}$, the ability to deliver wireless communication networks to the entire population was originally anticipated. The development of extremely reliable devices and the cellular idea have both contributed to the rapid rise of mobile communication systems. The idea of cellular played a key role when it comes to resolving the difficulties with spectral congestion and user capacity. It provided a large capacity with restricted allocation of spectrum and no major technological breakthroughs [7]. The signal that a cell receives must be strong in order to enclose a good quality transmission path of the signal. When a signal crosses the cell boundary, it becomes interference. As a result, channel frequencies are rarely reused in nearby cells. Co-channel interference may occur if it is reused cause signal reception in nearby cells to be harmed, and the service quality may be severely harmed [8], [9].

As a result, it's worth noting that models of transmission are frequently used to assess wireless route loss communication for various sorts of terrains. It is critical to assemble information about the environment of electromagnetic waves, such as the location of the transmitter and receiver, as well as the device's operating frequency. Based on building factors, Keenan et al developed a radio model for predicting coverage. The parameters used in this model's approach were generated from measurement data. In an indoor context, the model gives a quick and easy technique to anticipate route loss. As a result, it proved to be helpful in predicting primary coverage [10].

\section{EMPIRICAL MODEL}

\section{A. Egli Model}

The total route loss for a point-to-point link can be predicted using this approach. It is calculated by using the following equation [11]:

$$
P L_{50}=G_{b} G_{m}\left(h_{b} h_{m} / I^{2}\right)^{2} \beta
$$

where,

$G_{m}$ is antenna gain of a mobile;

$G_{b}$ is antenna gain at the base station;

$h_{b}$ is antenna height at base station;

$h_{m}$ is antenna height for mobile phones;

$I$ is distance of propagation;

$\beta=(40 / f)^{2}, f$ is the frequency in $\mathrm{MHz}$.

\section{B. Two Ray Ground Reflection (TRGR) Model}

This model takes into account both the direct and ground reflection paths. The received power at distance $\mathrm{d}$ is predicted by the following equation [12]:

$$
P_{r}(d)=\frac{P_{t} G_{t} G_{r} h_{t}^{2} h_{r}^{2}}{d^{4} L}
$$

where,

$h_{t}$ and $h_{r}$ are the heights of the transmitted and received antennas respectively;

$P_{t}$ is the transmitted signal power and $L=1$;

$G_{t}$ and $G_{r}$ are the antenna gains of the transmitter and the receiver respectively.

\section{Free Space Path Loss Model}

When the transmitter and receiver are separated by a clear Line Of Sight (LOS) path, this model is utilised to determine the received signal strength. The well-known Friis transmission equation gives the power received in open space $\left(P_{r}\right)$ [11]:

$$
P_{r}(d)=\frac{P_{t} G_{t} G_{r} \lambda^{2}}{(4 \pi)^{2} d^{2} L}
$$

where,

$d$ is the distance between the transmitter and the receiver in meters;

$G_{r}$ is gain of the receiving antenna;

$G_{t}$ is gain of the transmitter antenna;

$P_{t}$ is power that is transmitted;

$L$ is system loss factor is assumed to be one;

$\lambda$ is metre wavelength.

Calculation of Free Space Path Loss is done by using the following equation [12]: 


$$
P L_{f s}=32.45+20 \log _{10}(d)+20 \log _{10}(f)
$$

where,

$f$ is $\mathrm{MHz}$ stands for frequency;

$d$ is metre distance between transmitter and receiver.

The average path loss for an arbitrary path in the lognormal path loss propagation model, $L_{p}(d)$, is calculated as a function of distance $d$ regardless of the presence of a direct LOS between the transmitter and receiver units, by utilising a route loss exponent, [12]:

$$
L_{p}(d)=\left[\frac{d}{d_{0}}\right]^{n}
$$

where,

$n$ is rate at which the path loss rises with distance is indicated by the path loss exponent;

$d_{0}$ is Free-space close-in reference distance is a term that refers to the distance between two points in free space.

In large cellular systems, reference distances of $1 \mathrm{~km}$ and 1 mile are usually utilised, however in microcellular systems, much shorter distances are used. The path loss exponent's value $n$ that it is dependent on the propagation environment is given in Table 1.

TABLE 1

EXPONENT VALUES FOR PATH LOSS IN VARIOUS ENVIRONMENTS, [14]

\begin{tabular}{l||l}
\multicolumn{1}{c||}{ Environment } & Path Loss Exponent, n \\
\hline Obstructed in building & 4 to 6 \\
\hline Obstructed in factories & 2 to 3 \\
\hline Free space & 2 \\
\hline Cellular radio in cities & 2.7 to 3.5 \\
\hline $\begin{array}{l}\text { Urban cellular wireless in } \\
\text { the shadows }\end{array}$ & 3 to 5 \\
\hline $\begin{array}{l}\text { Line of sight is a term used in } \\
\text { construction. }\end{array}$ & 1.6 to 1.8 \\
\end{tabular}

However, studies in environments with similar features have revealed that path loss $P L\left(d_{i}\right)$ is a random variable around a mean value, a lognormal distribution $P L\left(d_{0}\right)$, which expressed in $\mathrm{dB}$ as, [5], [6]:

$$
P L\left(d_{i}\right)=P L\left(d_{0}\right)+10 n \log \left[\frac{d_{i}}{d_{0}}\right]
$$

where, the path loss at the reference distance is the first portion $d_{0}$ and the distance determines the second portion $d_{\mathrm{i}}$ together with the path-loss exponent $n$.

Furthermore, the path loss $P L\left(d_{i}\right)$ (in $\mathrm{dB}$ ) it's also possible to express it in terms of the mean $P L\left(d_{i}\right)$, plus a random variable $X_{Q}$, which has a Gaussian distribution and a zero mean as, [13]:

$$
P L\left(d_{i}\right)=P L\left(d_{0}\right)+10 n \log \left[\frac{d_{i}}{d_{0}}\right]+X_{Q}
$$

where $X_{Q}$ is a distributed random variable with a Zero-Mean Gaussian mean (in $\mathrm{dB}$ ) and a Standard Deviation (SD) which is marked by $Q$ (in $\mathrm{dB})$.

where:

$$
n=\frac{P L\left(d_{i}\right)-P L\left(d_{0}\right)}{10 n \log \left[\frac{d_{i}}{d_{0}}\right]}
$$

as, the term $P L\left(d_{i}\right)$ represents Measured path loss or $\left(P_{m}\right)$, and $P L\left(d_{0}\right)$ represents the Predicted path loss or $\left(P_{r}\right)$.

\section{COST 231 Hata Model}

The Hata model (COST 231) is a widely used model for predicting route loss in mobile wireless systems. The Hata model COST 231 is intended for use in the $500 \mathrm{MHz}$ to 2000 $\mathrm{MHz}$ frequency range. It was created as a follow-up to Hatamodel. Okumura's Corrections are also included for places that are urban, suburban, or rural (flat). Despite the fact that its frequency range is outside that of the measurements, it is often employed in this frequency band for path loss prediction due to its simplicity and availability of correction factors. The basic equation for calculating route loss in decibels is as follows, [11]:

$P L=46.3+33.9 \log _{10}(f)-13.82 \log _{10}\left(h_{b}\right)-a h_{m}$

$+\left(44.9-6.55 \log _{10}\left(h_{b}\right)\right) \log _{10} d+c_{m}$

where,

$f$ is frequency in $\mathrm{MHz}$;

$d$ is the distance in kilometres between the antennas of the Base Station (BS) and the Customer Premises Equipment (CPE);

$h_{b}$ is the height of the AP antenna above ground level in metres.

Furthermore, for suburban or open surroundings, the parameter cm is set to $0 \mathrm{~dB}$, whereas for urban contexts, it is set to $3 \mathrm{~dB}$. The parameter $a h_{m}$ for urban surroundings, is defined as [15]:

$\mathrm{a} h_{m}=3.20\left(\log _{10}(11.75 \mathrm{hr})^{2}-4.97\right.$, for $\mathrm{f}>400 \mathrm{MHz}$ (13)

Also, it is defined as well as in suburban and rural (flat) surroundings [15]:

$\mathrm{a} h_{m}=\left(1.1 \log _{10} f-0.7\right) h_{r}-\left(1.56 \log _{10} f-0.8\right)$

where,

$h_{r}$ is the height of the CPE antenna above ground level in metres.

By focusing on (2) to (4), the path loss exponent of the predictions generated by the COST 231 Hata model has been determined to be: 
$N_{\text {COST } 231}=\left(44.9-6.55 \log _{10}\left(h_{b}\right)\right) / 10$

\section{E. Young Model}

The behaviour of large-city cellular communication systems is depicted in this model. The following equation is used to calculate it [16]:

$$
P L=G_{B} G_{M}\left[\frac{h_{B} h_{M}}{d^{2}}\right]^{2} \beta
$$

where,

$P L$ is path loss in $\mathrm{dB}$;

$G_{B}$ is dB gain of the base transmitter;

$G_{M}$ is dB gain of a mobile transmitter;

$h_{B}$ is antenna height of base station in metres;

$h_{M}$ is antenna height of base station in metres;

$d$ is $\mathrm{km}$ distance between two points;

$\beta$ is factor of clutter.

\section{SIMULATION DESCRIPTION}

Using the Matlab implementation for subsequent investigations to evaluate the provided models by comparing the bearable predictions with the experimental data is a less involved but more successful way. The generated path loss findings from the proposed models might compare to the foretelling loss produced by certain empirical models to test the correctness of the presented models. As a result, additional information regarding models and scenarios for simulation using MATLAB R2015b software is provided in this section. The Egli model, Two Ray Ground Reflection (TRGR) model, Free Space model, Cost 231 Hata model, and Young model are all discussed in this section in both urban and rural settings. The route loss of channel propagation models is estimated during simulations. We fixed the operating frequency of all simulation scenarios to $2.1525 \mathrm{GHz}$ using the MATLAB R2015b program's script property and constructing the simulation codes. In the simulation, we used a distance of approximately 2 $\mathrm{km}$ between transmitter and receiver, with a base station transmitter strength of $60.79 \mathrm{dBm}$. Moreover, Table 2, indicates the values of the parameters that were used in this study.

TABLE 2

PARAMETERS OF NUMERICAL SIMULATIONS

\begin{tabular}{|c|c|c|}
\hline Parameters & Urban & Rural \\
\hline $\begin{array}{l}\text { Distance between transmitter } \\
\text { and receiver }\end{array}$ & $2 \mathrm{~km}$ & \\
\hline Mobile transmitter power & $35 \mathrm{dBm}$ & \\
\hline Transmitter antenna height & $1.5 \mathrm{~m}$ & \\
\hline Correction for shadowing & $7 \mathrm{~dB}$ & \\
\hline Frequency & $2.1525 \mathrm{GHz}$ & \\
\hline Base station transmitter power & $60.79 \mathrm{dBm}$ & \\
\hline
\end{tabular}

Eight trials were used in the simulations. In both urban and rural settings, path loss was computed using all of the previously listed characteristics throughout each experiment. In the computation, the operational frequency and transmitter-toreceiver distance are set to $2.1525 \mathrm{GHz}$ and $2 \mathrm{~km}$, respectively. The flow chart for the calculating procedure that was used for the chosen models could be seen in Fig. 1. This flow chart implies the steps of the computed path loss results as path loss calculation considered to be one of the major factors that we have to estimate in order to have the ability to predict the accurateness of the radio propagation behavior. Calculation protocol could be briefly summarized as follows:

Used software: MATLAB R2015b.

Simulation time on average: $54 \mathrm{sec}$ for each run.

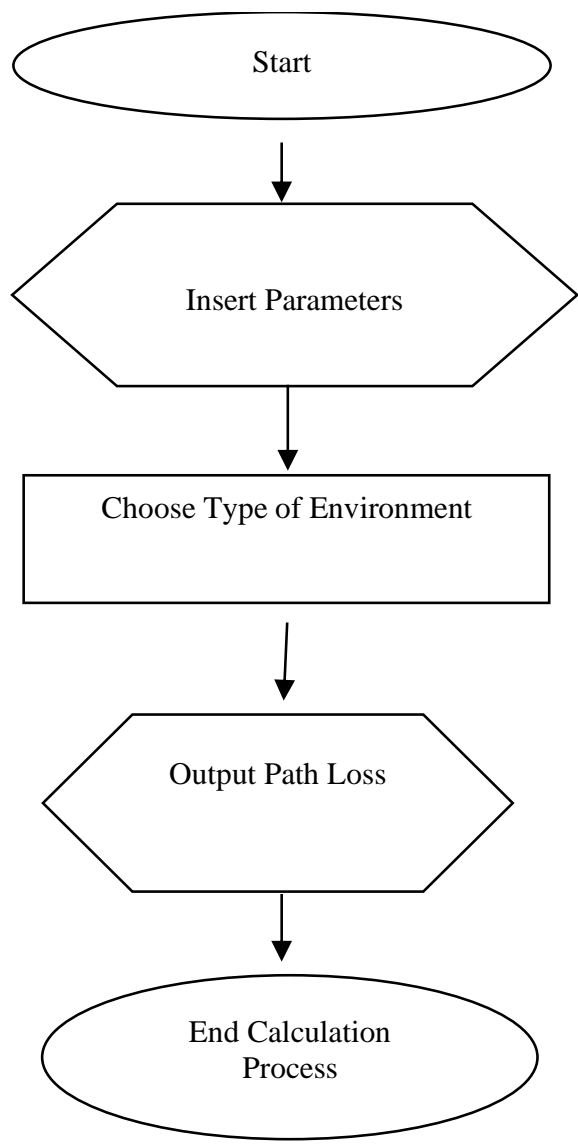

Fig. 1: Calculation process flow chart

\section{SIMULATION RESULTS}

To evaluate the design parameters of the proposed models, it was recommended to use one of the computer simulations. Various propagation models are investigated and contrasted in this section. Various propagation models were calculated and analysed (Egli, TRGR, Free Space, COST 231 Hata, Young). In both urban and rural settings, propagation models were tested at a frequency of $2.1525 \mathrm{GHz}$. The numerical findings of the selected urban models are displayed in Fig. 2. 


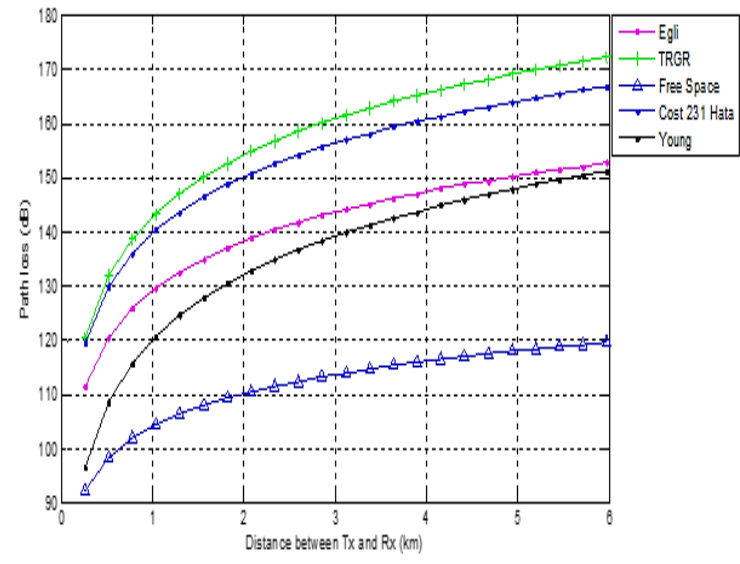

Fig. 2: Path loss in urban environment

In an urban context, the route loss calculation of the Free Space model yields (117 dB). In a rural setting, it is evident that the Egli model has the maximum path loss value. In an urban context, the TRGR model had the highest value $(174 \mathrm{~dB})$. The numerical results of the models in rural areas are displayed below Fig. 3.

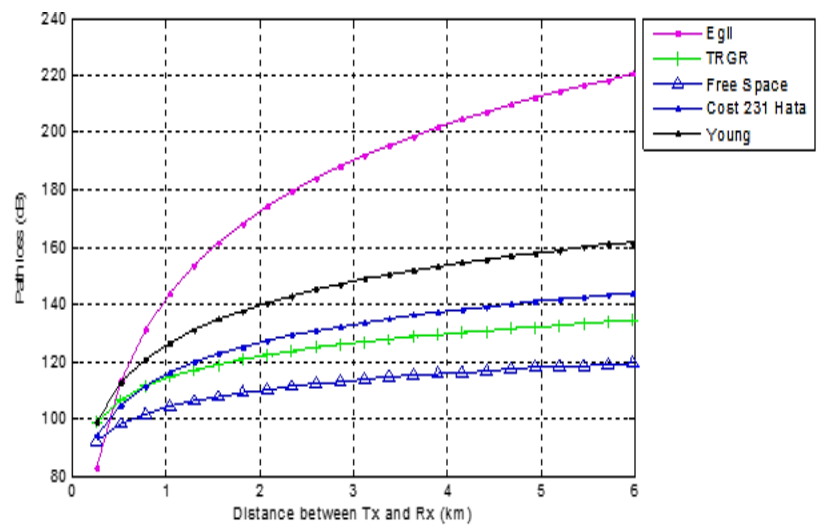

Fig. 3: Path loss in rural environment

When comparing the path loss estimation's results in rural environments to the results of the other models, it was clear that the Free Space model had the lowest route loss result $(118 \mathrm{~dB})$ in comparison to other models. Furthermore, in a rural area, the Egli model had the largest path loss result $(220 \mathrm{~dB})$ when compared to the other models.

As previously said, the results of computer simulations should be analysed in order to confirm the outcomes of future models. The results analysis of the path loss values for the above propagation models (Egli, TRGR, Free Space, COST 231 Hata, Young) in urban and rural environments are shown in Figs. 4 and 5, respectively.

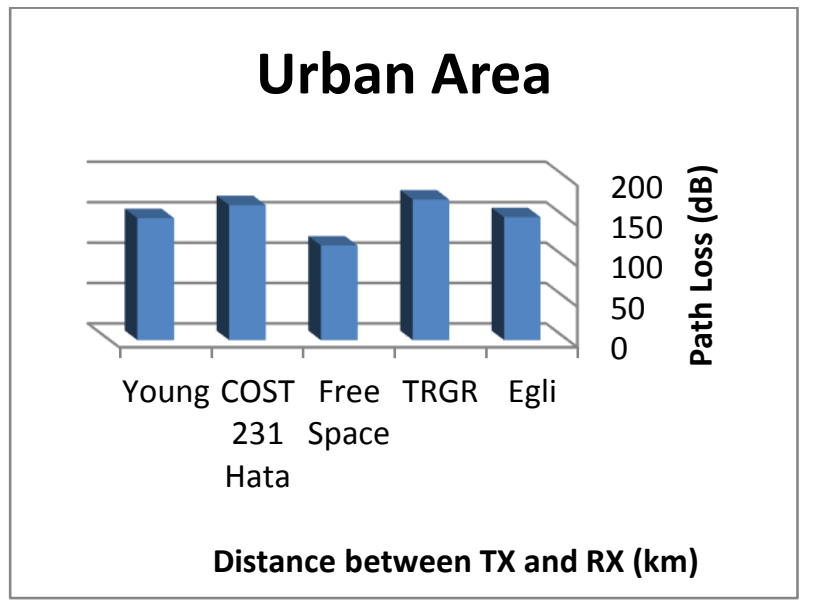

Fig. 4: Analysis of results in urban area

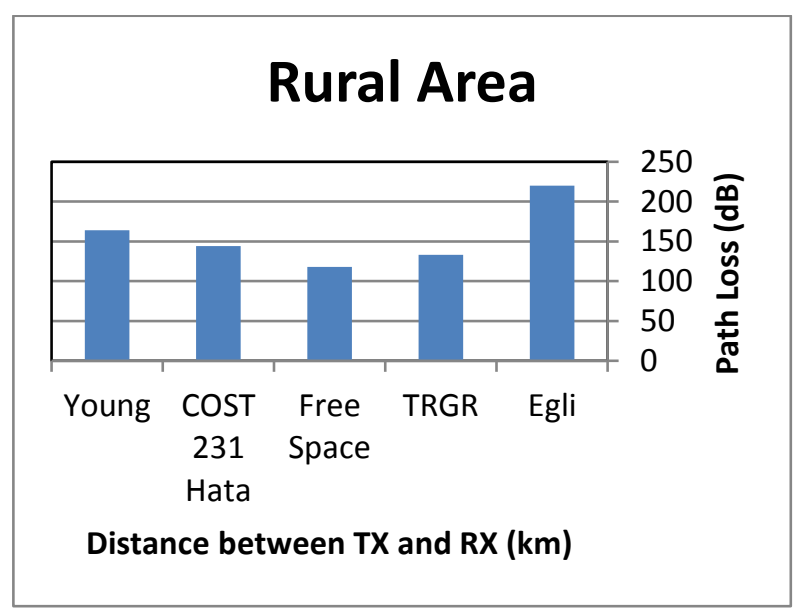

Fig. 5: Analysis of results in rural area

When comparing the findings of the path loss estimation with the results of the other models in a rural area, the Egli model clearly produced the highest route loss estimates (220 dB). However, in this study, special attention should be made to the output of the Free Space model's route loss estimation, which is $(117 \mathrm{~dB})$ as the lowest value in an urban environment.

In the next part, various measurements were taken to demonstrate the proposed models.

\section{EXPERIMENTAL METHODS}

\section{A. Measurement Methodology}

Measurements were taken in this part to see how they affected the sensitivity response of the models and signal propagation. The spectrum analyser FSH6 was used to evaluate measured data surrounding the National Telecommunication Institute's campus in Cairo, Egypt. Measurement configurations are shown in Table 3. Furthermore, the work place arrangement using FSH6 spectrum analyzer is shown in Fig. 6. It was decided to employ the frequency band of $2.1525 \mathrm{GHz}$ to investigate the behaviour of signal attenuation during the test 
setup because this frequency is the most acceptable licenced spectrum at National Telecommunication Institute.

TABLE 3

MEASUREMENT CONFIGURATIONS

\begin{tabular}{l|l}
$R X$ cable loss & $4.2 \mathrm{~dB}$ \\
\hline$T X$ antenna power & $60.79 \mathrm{dBm}$ \\
\hline TX feeder cable & loss $2.4 \mathrm{~dB}$ \\
\hline TX antenna & ANT-ASI4518R10v06 \\
\hline Frequency & $2.1525 \mathrm{GHz}$ \\
\hline$R X$ antenna & Isotropic \\
\hline Receiver & FSH6 spectrum analyser
\end{tabular}

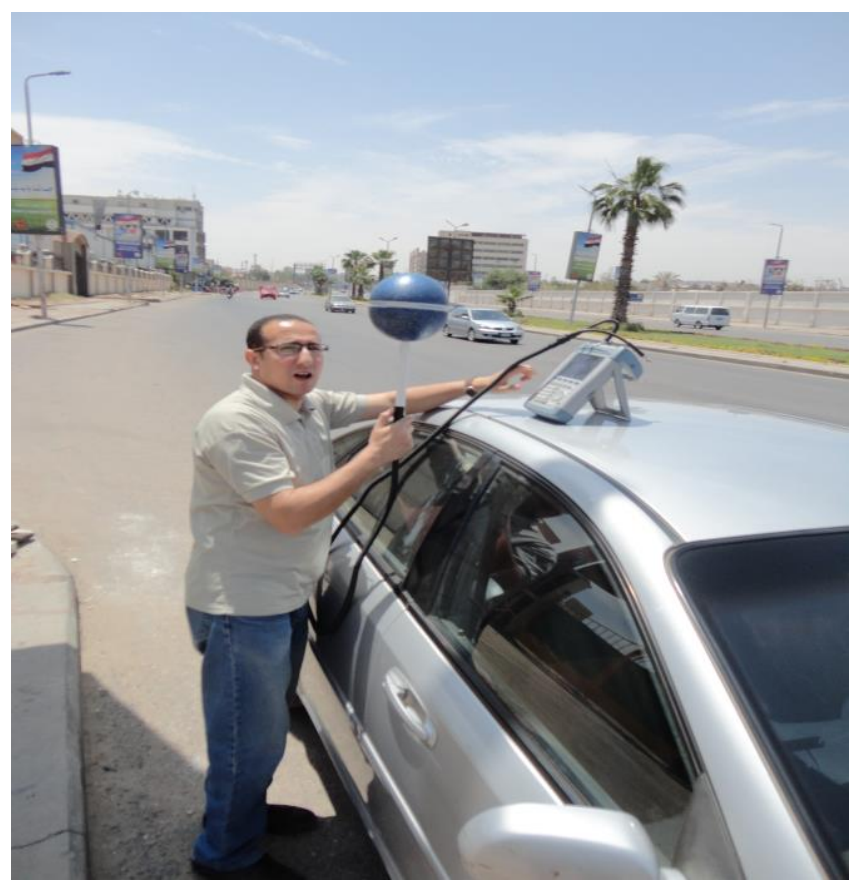

Fig. 6: Work place arrangement using FSH6 spectrum analyzer

\section{B. Measurement Environments}

The first and second measurement sites reflected a typical urban setting with somewhat elevated buildings, sparse greenery, medium-sized dwellings, and wide streets. Furthermore, the bulk of roadways are rectilinear and wide. The typical building height in this setting is less than 19 metres, and the most common building materials are strong concrete and brick. In addition, concrete and brick are the most often utilised building materials in the area. Buildings cover around $55 \%$ of the land, while vegetation covers the remaining 7\%. The third measuring location, on the other hand, showed a rural region. The three measurement locations are shown in Fig. 7. The measured sites' coordinates are listed as below in Table 4.

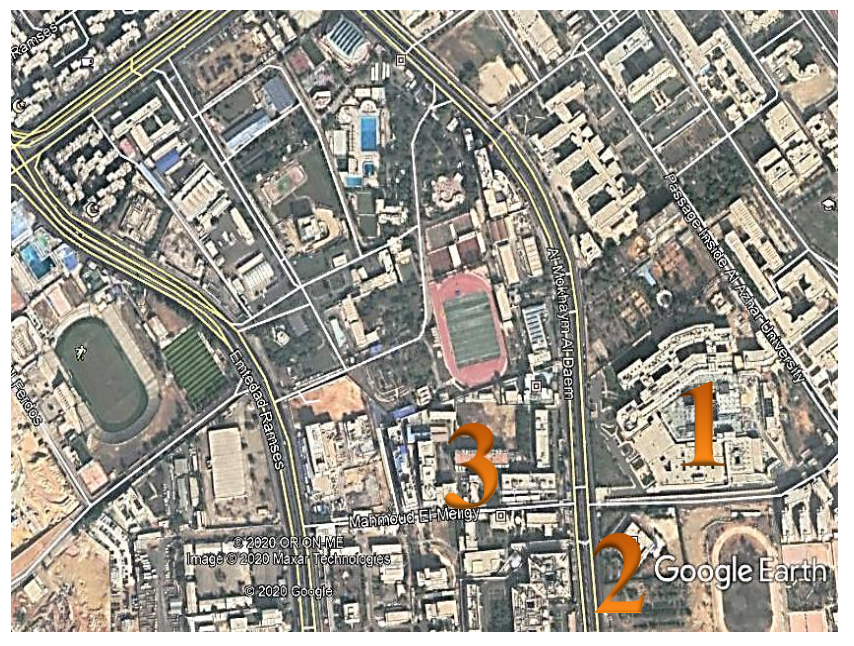

Fig. 7: Measurement locations

TABLE 4

COORDINATES OF MEASURED SITES

\begin{tabular}{l|l|c|c}
\multirow{2}{*}{$\begin{array}{c}\text { Site } \\
\text { Number }\end{array}$} & \multicolumn{1}{|c}{ Address } & \multicolumn{2}{c}{ Coordinates } \\
\cline { 3 - 4 } 1 & $\begin{array}{l}\text { National Telecommunication } \\
\text { Institute backyard }\end{array}$ & 300314.13 & 311838.36 \\
\hline 2 & $\begin{array}{l}\text { National Telecommunication } \\
\text { Institute front door }\end{array}$ & 300312.57 & 311838.51 \\
\hline 3 & Emtedad Ramses street & 300317.53 & 311825.95
\end{tabular}

Third measurement assessment took place in a rural area that reflected an ideal rural environment, with short structures, significantly more greenery than metropolitan areas, and narrow streets. The average building height in this setting is less than 13 meters, with two to four stories, and the most usually utilized building materials are concrete and brick. Buildings cover around $35 \%$ of the land, while vegetation covers the remaining $14 \%$.

The tracks were constant right away from the transmitter since the goal of those measurements was to examine the behaviour of signal attenuation and propagation steep, however, the receiver was taking several samples over the journey distance in order to calculate the large average values. To capture channel response, a spectrum analyzer FSH6 with a frequency range of $100 \mathrm{KHz}$ to $6 \mathrm{GHz}$ was mounted in a moving car. In addition, the measured route loss for the relaying system in outside conditions was acquired. The measures survey was carried out in collaboration with Aswan University and the National Research Centre (NRC). With the help of the National Telecommunication Institute, measurement scanning was completed.

\section{Scope of Measurement Survey}

The following is a brief summary of the measurement protocol:

Used equipment: transmitting antenna ANTASI4518R10v06 and a spectrum analyzer FSH6 ranged from $100 \mathrm{KHz}$ up to $6 \mathrm{GHz}$ connected with isotropic antenna.

Measurement environments: around the National Telecommunication Institute's campus. The distance between three points is measured. The first and second measurements were taken in the backyard and front entrance of the National 
Telecommunication Institute, respectively. Emtedad Ramses Street was the site of the third measuring survey.

Each scenario was investigated to see how the signal attenuation and propagation inclination behaved in each site. Specific measures that were regarded additional away for parameter modification and route loss analysis, samples from the transmitter that were determined to be quite far from the plurality of values were eliminated for the purpose of removing noise in measurement produced by a few stumbling blocks. Transmitted power was measured using a spectrum analyzer FSH6 with a frequency range of $100 \mathrm{KHz}$ to $6 \mathrm{GHz}$. Using FSH view software, the measured findings were saved in the spectrum analyzer and transferred to a PC.

\section{MEASUREMENT RESULTS}

To calculate the measured data, the following equation was utilized [5]:

Path Loss $(\mathrm{dB})=$ Tx Power $(\mathrm{dBm})-\mathrm{Rx}$ Power $(\mathrm{dBm})$

Moreover, the measured route loss for the three locations is presented below Table 5 .

TABLE 5

MEASURED PATH LOSS FOR THREE LOCATIONS

\begin{tabular}{l|l|l|l} 
Distance & $\begin{array}{c}\text { First Site } \\
\text { Measured }\end{array}$ & $\begin{array}{c}\text { Second Site } \\
\text { Measured }\end{array}$ & $\begin{array}{c}\text { Third Site } \\
\text { Measured }\end{array}$ \\
\hline$d i[m]$ & $P L[d B]$ & $P L[d B]$ & $P L[d B]$ \\
\hline 100 & 131.2 & 131.27 & 128.46 \\
\hline 200 & 131.28 & 131.2 & 128.74 \\
\hline 300 & 130.22 & 122.82 & 128.89 \\
\hline 400 & 131.59 & 122.77 & 129.23 \\
\hline 500 & 130.14 & 123.02 & 129.29 \\
\hline 600 & 131.09 & 123.04 & 129.34 \\
\hline 700 & 132.77 & 123.04 & 129.43 \\
\hline 800 & 132.1 & 123.02 & 129.48 \\
\hline 900 & 131.22 & 127.83 & 129.56 \\
\hline 1000 & 131.21 & 128.07 & 131.2 \\
\hline 1100 & 131.24 & 128.2 & 131.28
\end{tabular}

The measured route loss for the three sites near the National Telecommunication Institute, as seen in Fig. 8, is shown in the following figure.

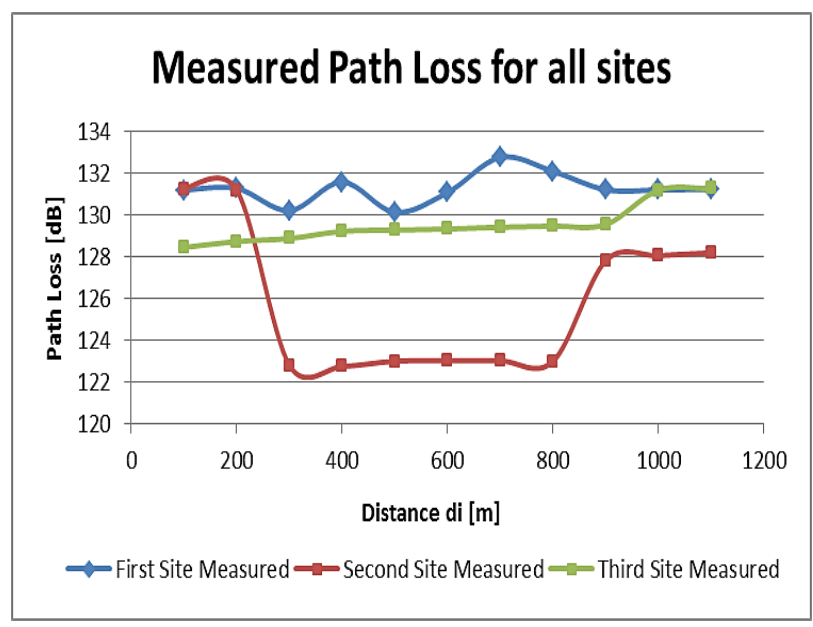

Fig. 8: Measured path loss of three sites
According to preceding findings, route loss due to diffraction might occur when a barrier appears in the way. However, misfortunes can occur as the signal diffracts around the item. The loss increases as the object becomes more adjusted, as radio signals tend to diffract more around sharp edges [17], [18]. This conclusion agrees also with [19], [20]. Furthermore, the estimations and measurements could be vulnerable for the propagation of guided waves marvel, as the road introduction and structure can aid in the propagation of radio waves, as the values of the cable misfortune and inclusion misfortunes could be evacuated to gauge the way constriction as it were due to propagation environment and to have exact assessment.

\section{MEASUREMENT ANALYSIS AND CALCULATION OF PATH LOSS EXPONENT}

According to equation (18) and the above description, equation (19) could be drived:

Rx Power $(\mathrm{dBm})=$ Tx Power $(\mathrm{dBm})+$ Gains $(\mathrm{dB})-$ Losses $(\mathrm{dB})$

$P_{r}=P_{t}-L_{c t}+G_{t}-P L+G_{r}-L_{c r}$

where,

$L_{c}$ is cable loss;

$G$ is antenna gain.

Generally, the route loss of a channel is defined as the ratio of transmitter to receiver power.

$P L=\frac{P_{t}}{P_{r}}$

or in $\mathrm{dB}$

$$
P L(d B)=10 \log _{10} \frac{P_{t}}{P_{r}} d B
$$

In statistical modelling, regression analysis is a set of statistical techniques for evaluating the relationships between variables.

For forecasting the distance of a reliable communication system, a simple power law path loss model as shown in equations (9) and (10) was adopted. As a result, a table representing path loss as a function of distance $d$ with the same quantity step $d$ was required to find exponent $\mathrm{n}$ in equation (9). The step was 100 metres long.

For the following reasons, the basic power law path loss model was used for forecasting the length of a secure connection:

1) The route loss concept, which is a measure of average radio frequency attenuation, is used in the model.

2) It's also important to remember that free space path loss refers to the decrease in signal intensity of an electromagnetic wave caused by a line-of-sight passage 
through free space with no impediments to induce reflection or diffraction.

3) It is more convenient to characterise the path loss in terms of a direct loss because this allows you to calculate elements like the expected signal.

Path loss exponent $\mathrm{n}$ can be calculated using linear regression analysis by minimising the difference between observed $\left(P_{m}\right)$ and anticipated $\left(P_{r}\right)$ values in equation $(11)$ to yield:

$$
n=\frac{\sum_{i=1}^{k}\left[\operatorname{Pm}\left(d_{i}\right)-\operatorname{Pr}\left(d_{0}\right)\right]}{\sum_{i=1}^{k} 10 \log \left(\frac{d_{i}}{\boldsymbol{d}_{\mathbf{0}}}\right)}
$$

where,

$P_{m}\left(d_{i}\right)$ indicates the route loss that has been measured;

$P_{r}\left(d_{o}\right)$ reflects the route loss that is expected;

$d_{o}=$ distance $=100 \mathrm{~m}$;

$k$ is the number of data points or sample points that have been collected.

The Standard Deviation denoted by $Q$ is equally minimized using the following formula [20]:

$$
Q=\sqrt{\sum \frac{\left(P_{m}-P_{r}\right)^{2}}{N-1}}
$$

where,

$P_{\mathrm{m}}$ is measured path loss;

$P_{\mathrm{r}}$ is predicted path loss;

$N$ is number of measured data points.
When the values are obtained in a method that expedites out the component of fading quickly, a high standard deviation of error between predicted and measured samples is thought to be a reliable indicator of shadow fading. The distinction between the two should be highlighted $P L\left(d_{\mathrm{i}}\right)-P L\left(d_{0}\right)$, this also represents the disparity between the two $\left(P_{\mathrm{m}}-P_{\mathrm{r}}\right)$ which is an error term with respect to $n$, and the sum of the mean squared error, $\varepsilon(n)$. The following equation describes this error [5], [20]:

$$
\varepsilon(n)=\sum_{i=1}^{k}\left[\operatorname{Pm}\left(d_{i}\right)-\left(\operatorname{Pr}\left(d_{0}\right)+10 n \log \left(\frac{d_{i}}{d_{0}}\right)\right)\right]^{2}=\sum_{i=1}^{k}[a+n \mathrm{~b}]^{2}
$$

where,

$$
\begin{aligned}
& a=P L\left(d_{i}\right)-P L\left(d_{0}\right) \\
& b=-10 \log \left(\frac{d_{i}}{d_{0}}\right) \\
& c=a+n b
\end{aligned}
$$

Then

$$
\varepsilon(n)=c^{2}=a^{2}+2 a n b+(n b)^{2}
$$

\begin{tabular}{|c|c|c|c|c|c|c|}
\hline Distance & Measure & $\mathbf{a}$ & b & $\mathbf{a}^{2}$ & $\mathbf{b}^{2}$ & $2 \mathbf{a b}$ \\
\hline $\operatorname{di}[m]$ & $P L(d i)$ & $P L(d i)-P L(d o)$ & $-10 \log \left(\frac{d_{i}}{d_{0}}\right)$ & & & \\
\hline 100 & 131.2 & 0 & 0 & 0 & 0 & 0 \\
\hline 200 & 131.28 & 0.08 & -3.01029 & 0.0064 & 9.06184 & -0.48164 \\
\hline 300 & 130.22 & -0.98 & -4.77121 & 0.9604 & 22.76444 & 9.35157 \\
\hline 400 & 131.59 & 0.39 & -6.02059 & 0.1521 & 36.24750 & -4.69606 \\
\hline 500 & 130.14 & -1.06 & -6.98970 & 1.1236 & 48.85590 & 14.81816 \\
\hline 600 & 131.09 & -0.11 & -7.78151 & 0.0121 & 60.55189 & 1.711932 \\
\hline 700 & 132.77 & 1.57 & -8.45098 & 2.4649 & 71.41906 & -26.5360 \\
\hline 800 & 132.1 & 0.9 & -9.03089 & 0.81 & 81.55697 & -16.2556 \\
\hline 900 & 131.22 & 0.02 & -9.54242 & 0.0004 & 91.05777 & -0.38169 \\
\hline 1000 & 131.21 & 0.01 & -10 & 0.0001 & 100 & -0.2 \\
\hline \multirow[t]{2}{*}{1100} & 131.24 & 0.04 & -10.4139 & 0.0016 & 1149.8393 & -0.83311 \\
\hline & & & Total & 5.5316 & 1671.3546 & -23.5024 \\
\hline
\end{tabular}

This analysis includes a comparison of the regression analysis predictions with the results of this analysis. The findings of the expected path loss for first, second and third measured sites are shown in Tables 6,7 and 8, respectively.

TABLE 6

PREDICTED PATH LOSS FOR FIRST MEASURED SITE 
TABLE 7

PREDICTED PATH LOSS FOR SECOND MEASURED SITE

\begin{tabular}{|c|c|c|c|c|c|c|}
\hline Distance & Measure & $\mathbf{a}$ & b & $\mathbf{a}^{2}$ & $\mathbf{b}^{2}$ & $2 \mathrm{ab}$ \\
\hline$d i[m]$ & $P L(d i)$ & $P L(d i)-P L(d o)$ & $-10 \log \left(\frac{d_{i}}{d_{0}}\right)$ & & & \\
\hline 100 & 131.27 & 0 & 0 & 0 & 0 & 0 \\
\hline 200 & 131.2 & -0.07 & -3.01029 & 0.0049 & 9.06184 & 0.42144 \\
\hline 300 & 122.82 & -8.45 & -4.77121 & 71.4025 & 22.76444 & 80.6334 \\
\hline 400 & 122.77 & -8.5 & -6.02059 & 72.25 & 36.24750 & 102.350 \\
\hline 500 & 123.02 & -8.25 & -6.98970 & 68.0625 & 48.85590 & 115.330 \\
\hline 600 & 123.04 & -8.23 & -7.78151 & 67.7329 & 60.55189 & 128.0836 \\
\hline 700 & 123.04 & -8.23 & -8.45098 & 67.7329 & 71.41906 & 139.1031 \\
\hline 800 & 123.02 & -8.25 & -9.03089 & 68.0625 & 81.55697 & 149.0096 \\
\hline 900 & 127.83 & -3.44 & -9.54242 & 11.8336 & 91.05777 & 65.65184 \\
\hline 1000 & 128.07 & -3.2 & -10 & 10.24 & 100 & 64 \\
\hline \multirow[t]{2}{*}{1100} & 128.2 & -3.07 & -10.4139 & 9.4249 & 1149.8393 & 63.94134 \\
\hline & & & Total & 446.7467 & 1671.3546 & 908.5243 \\
\hline
\end{tabular}

TABLE 8

PREDICTED PATH LOSS FOR THIRD MEASURED SITE

\begin{tabular}{|c|c|c|c|c|c|c|}
\hline Distance & Measure & $\mathbf{a}$ & b & $\mathbf{a}^{2}$ & $\mathbf{b}^{2}$ & 2ab \\
\hline $\operatorname{di}[\mathrm{m}]$ & $P L(d i)$ & $P L(d i)-P L(d o)$ & $-10 \log \left(\frac{d_{i}}{d_{0}}\right)$ & & & \\
\hline 100 & 128.46 & 0 & 0 & 0 & 0 & 0 \\
\hline 200 & 128.74 & 0.28 & -3.01029 & 0.0784 & 9.06184 & -1.68576 \\
\hline 300 & 128.89 & 0.43 & -4.77121 & 0.1849 & 22.76444 & -4.10324 \\
\hline 400 & 129.23 & 0.77 & -6.02059 & 0.5929 & 36.24750 & -9.2717 \\
\hline 500 & 129.29 & 0.83 & -6.98970 & 0.6889 & 48.85590 & -11.6029 \\
\hline 600 & 129.34 & 0.88 & -7.78151 & 0.7744 & 60.55189 & -13.6954 \\
\hline 700 & 129.43 & 0.97 & -8.45098 & 0.9409 & 71.41906 & -16.3949 \\
\hline 800 & 129.48 & 1.02 & -9.03089 & 1.0404 & 81.55697 & -18.4230 \\
\hline 900 & 129.56 & 1.1 & -9.54242 & 1.21 & 91.05777 & -20.9933 \\
\hline 1000 & 131.2 & 2.74 & -10 & 7.5076 & 100 & -54.8 \\
\hline \multirow[t]{2}{*}{1100} & 131.28 & 2.82 & -10.4139 & 7.9524 & 1149.8393 & \begin{tabular}{|l|}
-58.7343 \\
\end{tabular} \\
\hline & & & Total & 20.9708 & 1671.3546 & -209.704 \\
\hline
\end{tabular}

Then, the equations for mean squared error, $\varepsilon(n)$ are as follows:

First measured site:

$$
\varepsilon(n)=1671.3546 n^{2}-23.5024 n+5.5316
$$

Second measured site:

$$
\varepsilon(n)=1671.3546 n^{2}-908.5243 n+446.7467
$$

Third measured site:

$$
\varepsilon(n)=1671.3546 n^{2}-209.704 n+20.9708
$$

Then, we obtain the value of $n$ by minimizing the Mean Square Error (MSE) by equating the derivative of equation (8) to zero [20].

$$
\frac{\partial \varepsilon(n)}{\partial n}=0
$$

Therefore, after derivation the path loss exponent $(n)$ is:

First measured site:

Second measured site:

Third measured site:

The primary cause of a decrease in the energy density of an electromagnetic wave as it propagates through the environment is clearly signal pathway loss [21]. This description and conclusion agree with [22], [23]. As a result, it's crucial to notice that the path loss exponent $(n)$ is an important figure to consider when devising a radio signal generation strategy. We demonstrate some consequences of existing research findings in this section, as the interaction of electromagnetic radiation 
with the environment reduces the signal's quality as it travels from the transmitter to the destination, resulting in route loss. Furthermore, because they aim to identify how a radio broadcast changes from the transmitter to the receiver throughout its course, propagation models constitute the foundation for channel estimation. Moreover, the gained results from this work could be helpful for network planners and researchers before future site specific installation as a guide and evidence materials. The accuracy of our measurements results confirm and emphasize the importance of path loss exponent (n) factor in channel modeling of wireless communication systems. Also, our research results clarify that during a mobile call, there could be some distortions regarding the quality of the signal based on the location of the receiver and the distance between the transmitter and receiver. Furthermore, the findings of this study revealed that in metropolitan settings, longer distances influenced path loss estimation. Also, after 18 metres from the measurement survey, $23 \mathrm{~dB}$ loss was found at the start of the measurement in an urban area. Thus, to develop a wireless system, you must first understand the causes of radio route loss and be able to detect the signal loss levels for each radio path.

\section{DISCUSSION}

In this section, we'll go through some of the findings from our research. As a result of the preceding findings and debate, the following observations can be made:

1) Our research described that the interaction between the electromagnetic waves and the environment decreases the signal quality which is sent from transmitter to receiver that causes the path loss. Moreover, propagation models are the base for channel modelling as they try to describe the way a radio signal changes during its travel from the transmitter to the receiver.

2) Unfavorable receiver placement results in a large increase in path loss.

3) Path loss increases as the distance between the transmitter and the receiver grows.

4) Civilian areas are identified by increasing path loss at greater distances.

5) The slope of path loss changes over the range of recorded distances, with the decrease being steeper as the distance from the transmitter grows.

6) These measurements would be beneficial to researchers in the scope of site planning of the link budget of a telecommunication system.

The outcomes of this study will be beneficial as a guide and evidence materials for network planners and researchers prior to future site-specific installation. The proposed models were found to agree with various well-known models and observations. The path loss exponents are the most essential model parameters obtained from the results analysis, as previously noted from the above results and discussion up to this time. These data shed light on the wireless signal's distancedependent attenuation, which is thought to be the most major route loss driver. As a result, it is obvious that the model performs similarly well in terms of analytical accuracy.

\section{Conclusion}

The results of path loss measurement and numerical simulations were provided in this study, this information can be used to plan and develop wireless communication systems. One of the most important elements that we must assess is path loss. Furthermore, when developing a wireless communication network, a crucial issue that will offer us with the best path loss forecast is obtaining an accurate propagation model for propagation losses. The provided findings confirmed that route loss rises with increasing distance from the transmitter in a typical metropolitan area. As a result, we must emphasize the need of meticulously planning the transmitter's position during measurements, as this has a considerable impact on the results. As a result, estimating the route loss exponent $(n)$ is critical for cellular communication system radio signal propagation design. As a result of the cases studied in this study, it is clear that the value of path loss exponent $(n)$ is slightly greater in urban settings. Finally, because every radio signal will encounter attenuation as it travels from the transmitter to the receiver due to a number of processes, channel modelling is essential for defining the impulse response and measuring the path loss of a propagation channel.

\section{List of Abbreviations}

SIRCIM: Simulation of Indoor Radio Channel Impulse Response Model.

SUI: Stanford University Interim.

$I R$ : Incremental Relaying.

LOS: Line of Sight.

$P L$ : Path Loss.

$S D$ : Standard Deviation.

$C P E$ : Customer Premises Equipment.

$A P$ : Access Point.

TRGR: Two Ray Ground Reflection.

\section{ACKNOWLEDGMENT}

This research was supported by the Engineering Research Division, National Research Centre (NRC), Cairo and the Electrical Engineering Department, Faculty of Engineering, Aswan University.

\section{AUTHORS CONTRIBUTION}

Yahia A. Zakaria and Ehab K. I. Hamad did the following:

1. Research idea proposal.

2. Data collection and tools.

3. Experiments and Locations Survey.

4. Software.

5. Methodology.

6. Writing the research paper and interpretation. A. S. Abd Elhamid and K. M. El-Khatib did the following:

1. Research idea development. 
2. Methodology.

3. Data Analysis.

4. Drafting the article.

5. Investigation and writing the research paper.

\section{FUNDING STATEMENT:}

No financial support was received

\section{DECLARATION OF CONFLICTING INTERESTS STATEMENT:}

The author declared that there are no potential conflicts of interest with respect to the research authorship or publication of this article.

\section{REFERENCES}

[1]Maxwell, J, "A dynamical theory of the electromagnetic field," Philos. Trans. Roy. Soc. Lond, : 459-512, 1865.

[2] Schwab \& Fischer. 1998. Maxwell, Hertz, and German radio-wave history. Proc. IEEE 86: 1312-1318, 1998.

[3] Emagbetere \& Edeko, "Measurement of Validation of Hata like Models for radio Pathloss in Rural Environment at $1.8 \mathrm{GHz}$," Journal of Mobile Communications, 2009.

[4]Obot, A., Simeon, O., \& Afolayan J, "Comparative Analysis of Pathloss Prediction Models for Urban Microcellular," Nigerian Journal of Technology 30(3): 50-59, 2011.

[5]Y. Zakaria, E. Hamad, A. Abd Elhamid and K. El-Khatib, "Developed channel propagation models and path loss measurements for wireless communication systems using regression analysis techniques," BNRC Journal, 2021 DOI: https://doi.org/10.1186/s42269-021-00509-x

[6] Y. Zakaria, "Performance Analysis of Propagation Models for Cellular Mobile Communication Systems at $2.5 \mathrm{GHz}$," International Journal of Scientific and Engineering Research (IJSER), vol. 5, issue. 5, pp. 426-432, 2014.

[7] Andersen,.T. S. Rappaport, \& Youshida, "Propagation Measurement and Models for Wireless Communications Channels," IEEE Communications Magazine 33(1) :42-49, 1995.

[8] MacDonald, V. H, "The cellular concept," The Bell Systems Technical Journal 58(1) :15-43, 1979.

[9]Goodman, D.J. et al, "Packet Reservation Multiple Access for Local Wireless Communications," In proceedings of the IEEE 38 th Vehicular Technology Conference, Philadelphia, PA, USA, :701-706, 1988.

[10] Wilson, N.D., \& Rappaport, "Cellular Mobile Packet Radio Using Multiple-Channel CSMA,” IEEE Proc. F (GB) 132(6) : 517-526, 1985.

[11] E. Athanasiadou, A. R. Nix, and L.P. MeGeehan.: A Microcellular raytracing propagation model and evaluation of its narrowband and wideband predictions, IEEE journal on selected areas in communication., wireless comm., series, vol. 18 pp. 322-355, March 2000.

[12] Rappaport, T.S., Seidel, S.Y., \& Takamizawa, "Statistical channel impulse response models for factory and open plan building radio communication system design," IEEE Trans. Commun, :794-807, 1991.

[13] Erceg, V et al, "An empirically based path loss model for wireless channels in suburban environments," IEEE Journal on Selected Areas of Communications 17: 1205-1211, 1999.

[14] A. F. Molisch.: Wireless Communications, John Wiley \& Sons Ltd, 2005.
[15] D. Pareek, The Business of WiMAX, Chapter 2 and Chapter 4, John Wiley, 2006.

[16] Seybold, J.: Introduction to RF Propagation, John Wiley and Sons, 2005.

[17] Y. Zakaria, I. Glesk, "Propagation Measurements and Estimation of Channel Propagation Models in Urban Environment," the KSII Transactions on Internet and Information Systems Journal, vol. 11, no. 5, pp. 2453-2467, 2017.

DOI: $10.3837 /$ tiis. 2017.05 .008

[18] Y. Zakaria, "Performance Evaluation of Channel Propagation Models and Developed Model for Mobile Communication," American Journal of Applied Sciences, vol. 14, issue. 2, pp. 349-357, 2017.

DOI: http://thescipub.com/abstract/10.3844/ajassp.2017.349.357

[19] Rahul, B. Bansal, R. Kapoor, "Performance Analysis of Empirical Radio Propagation Models in Wireless Cellular Networks," World Scientific News, vol. 121, pp. 40- 46, 2019.

[20] Y. Zakaria, E. Hamad, A. Abd Elhamid and K. El-Khatib, "Propagation measurements and calculation of path loss exponent for outdoor cellular communication systems at $3.5 \mathrm{GHz}$," Radioelectronics and Communications Systems, vol. 64, no. 5, pp. 247-254, 2021. DOI: https://doi.org/10.3103/S0735272721050034

[21] Y. Zakaria, "Suggested Model for Wireless Communication in Suburban Environments with Estimation of Different Channel Models," 11th International Scientific Conference ELEKTRO 2016, Strbske Pleso - High Tatras, Slovakia, pp. 110-115, 2016. DOI: 10.1109/ELEKTRO.2016.7512046

[22] Majed, Abd. Rahman, "Propagation Path loss Modeling and Coverage Measurements in Urban Microcell in Millimeter Wave Frequency Bands," ARPN Journal of Engineering and Applied Sciences, vol. 13, no. 8, pp. 2882- 2887, 2018.

[23] Y. Zakaria, J. Hosek and J. Misurec, "Path Loss Measurements for Wireless Communication in Urban and Rural Environments," American Journal of Engineering and Applied Sciences, vol. 8, issue. 1, pp. 94 - 99, 2015.

DOI: 10.3844/ajeassp.2015.94.99

Arabic Title

$$
\begin{aligned}
& \text { تقييم أداء نمذجة القنو ات وقياسات فقدان المسار لأنظمة الاتصالات } \\
& \text { اللاسلكية في المناطق الحضرية و الريفية لانية الرية }
\end{aligned}
$$

\section{Arabic Abstract}

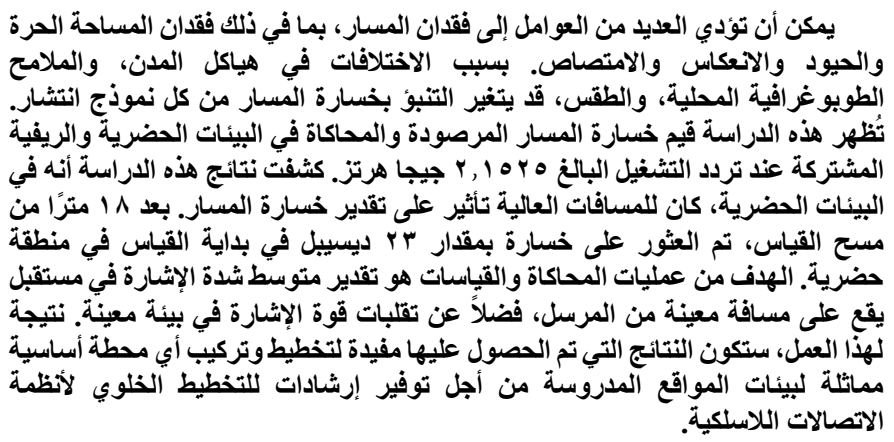

